\title{
Pijat Laktasi Dan Pijat Oksitosin Terhadap Onset Laktasi Di Kota Palangka Raya
}

\author{
Cia Aprilianti \\ Jurusan Kebidanan Poltekkes Kemenkes Palangka Raya \\ Email: chia.aprilianti@gmail.com
}

\begin{abstract}
ABSTRAK
Latar Belakang : Salah satu upaya yang dapat dilakukan untuk merangsang hormon oksitosin agar terjadi onset laktasi adalah dengan dilakukan pijat pada ibu postpartum. Pijat yang dimaksud ialah pijat laktasi dan pijat oksitosin.

Tujuan : Penelitian ini bertujuan untuk mengetahui hubungan onset laktasi pada ibu postpartum dengan jenis pijat yang diberikan.

Metode : Desain penelitian menggunakan Quasy Eksperimen, dengan rancangan Non-Equivalent Control Group Design. Besar sampel 40 ibu postpartum di Praktik Mandiri Bidan (PMB) di Kota Palangka Raya. Teknik pengambilan sampel secara purposive sampling. Analisis yang digunakan adalah uji Chi Square dan regresi logistik berganda.

Hasil : Ibu yang mendapatkan pijat laktasi semakin besar kemungkinan onset laktasinya cepat. Ibu yang mendapatkan pijat laktasi, 75\% mengalami onset laktasi lebih cepat. Dari nilai OR dapat disimpulkan bahwa ibu yang mendapatkan pijat laktasi mempunyai kecenderungan dengan onset laktasi cepat sebesar 5.57 kali lebih besar dibandingkan ibu yang mendapatkan pijat oksitosin. Disimpulkan onset laktasi pada ibu postpartum yang mendapatkan pijat laktasi lebih cepat daripada ibu postpartum yang mendapatkan pijat oksitosin. Inisiasi menyusu dini, paritas, dan indeks masa tubuh terbukti tidak mempunyai pengaruh yang signifikan terhadap onset laktasi pada ibu postpartum. Rekomendasi pijat laktasi menjadi salah satu layanan dalam praktik bidan mandiri.
\end{abstract}

Kata kunci: Onset Laktasi, Pijat Laktasi, Pijat Oksitosin

\section{PENDAHULUAN}

Pemberian Air Susu Ibu (ASI) eksklusif sampai usia 6 bulan tampaknya masih sulit untuk dilaksanakan, sehingga sasaran program perbaikan gizi masyarakat untuk meningkatkan ASI eksklusif menjadi $80 \%$ tampak terlalu tinggi, karena profil kesehatan Indonesia tahun 2016 menunjukkan cakupan bayi yang mendapatkan ASI sampai enam bulan hanya sebesar 29,5\%. (1) Di provinsi Kalimantan Tengah cakupan pemberian ASI Ekslusif pada bayi rata-rata hanya mencapai $20,5 \%$, khususnya di Kota Palangka Raya hanya sebesar 15,0\%. ${ }^{\text {(2) }}$ Manfaat pemberian ASI eksklusif menurut berbagai penelitian telah dapat menurunkan mortalitas dan morbiditas bayi $(\mathbf{3 , 4 )}$ mengoptimalkan pertumbuhan bayi, membantu perkembangan kecerdasan anak (5-7) dan membantu memperpanjang jarak kehamilan bagi ibu $\mathbf{( 3 , 8 , 9 )}^{\text {. Gagalnya }}$ pelaksanaan ASI eksklusif sering kali pada periode awal setelah persalinan karena ASI belum keluar, yang menjadi alasan ibu untuk memberikan susu formula. Pemberian makanan/minuman pralakteal adalah pemberian makanan atau minuman kepada bayi baru lahir sebelum ASI keluar (dengan kata lain mendahului pemberian ASI), 
biasanya telah dilakukan dalam 3 hari pertama. $(\mathbf{1 0 , 1 1 )}$

Onset laktasi yang terlambat memiliki peluang lebih kecil untuk dapat memberikan ASI secara eksklusif selama 6 bulan. Onset laktasi merupakan masa permulaan untuk memperbanyak air susu sampai air susu keluar pertama kali yang ditandai payudara terasa keras, berat, bengkak sampai air susu atau kolostrum keluar. ${ }^{\text {(12) Dikatakan onset }}$ laktasi cepat jika ASI keluar $\leq 72$ jam.

Faktor risiko yang dapat mempengaruhi terjadinya onset laktasi adalah umur, paritas, jenis persalinan, berat badan lahir, inisiasi menyusu dini, kecemasan, pijat oksitosin, dan status gizi. (13)

Umumnya, ASI keluar pada hari ke-2 atau ke-3 setalah persalinan,.Namun ada upaya yang dapat dilakukan untuk mempercepat keluarnya ASI yaitu dengan mempercepat onset laktasi dengan cara dilakukan pijat pada ibu postpatum.

Beberapa jenis pijat yang dapat dilakukan untuk membantu proses laktasi adalah pijat laktasi dan pijat oksitosin. Pijat laktasi adalah pemijatan yang dilakukan pada beberapa bagian tubuh, yaitu kepala, leher, bahu, punggung, dan payudara. Sedangkan pijat oksitosin, hanya pemijatan tulang belakang pada daerah punggung. Pada prinsipnya, kedua pijat ini ialah menimbulkan efek relaksasi untuk meningkatkan hormon oksitosin yang berperan sebagai hormon pengeluar ASI.

Perlu diberikan informasi dan pelayanan mengenai pijat pada ibu postpartum untuk meningkatkan proses laktasi dengan mempercepat terjadinya onset laktasi, baik pijat laktasi maupun pijat oksitosin. Rumusan masalah dalam penelitian ini adalah "Bagaimana pengaruh pijat laktasi dan pijat oksitosin terhadap onset laktasi pada ibu postpartum?". Tujuan penelitian ini secara umum untuk mengetahui hubungan onset laktasi pada ibu postpartum dengan jenis pijat yang diberikan. Secara khusus, tujuannya untuk mengetahui perbedaan proporsi onset laktasi pada ibu postpartum yang mendapatkan pijat laktasi dan pijat oksitosin, serta diketahuinya faktorfaktor yang mempengaruhi onset laktasi.

\section{METODE}

Jenis penelitian yang digunakan adalah Quasy Eksperimen dengan rancangan NonEquivalent Control Group Design. Jumlah sampel sebanyak 40 ibu postpartum di PMB di wilayah kota Palangka Raya pada bulan Februari-Maret 2018. Kelompok intervensi adalah ibu postpartum yang dilakukan pijat laktasi (20) sedangkan kelompok kontrol adalah ibu postpartum yang dilakukan pijat oksitosin (20). Pengambilan sampel dengan teknik purposive sampling. Uji statistik dengan menggunakan Chi Square dan regresi linier berganda.

\section{HASIL}


Tabel 1. Distribusi Karakteristik Responden di Wilayah Kota Palangka Raya

\begin{tabular}{lccc}
\hline & Variabel & $\mathrm{f}(\mathrm{n}=40)$ & $\%$ \\
\hline Jenis Pijat & $:$ Laktasi & 20 & 50 \\
& Oksitosin & 20 & 50 \\
\hline \multirow{2}{*}{ Onset Laktasi } & $:$ Lambat & 18 & 45 \\
& Cepat & 22 & 55 \\
\hline \multirow{2}{*}{ Indeks Massa Tubuh } & : Obesitas & 11 & 27.5 \\
& Underweight & 4 & 10 \\
& Normal & 25 & 62.5 \\
\hline Paritas & $:$ Multipara & 26 & 65 \\
& Primipara & 14 & 35 \\
\hline Inisiasi Menyusui Dini :Tidak & 18 & 45 \\
& Ya & 22 & 55 \\
\hline \multicolumn{5}{l}{} & &
\end{tabular}

Pijat laktasi diberikan kepada 20 (50\%) ibu postpartum, dan pijat oksitosin diberikan kepada $20(50 \%)$ ibu postpartum. Hasil analisa menunjukkan ibu postpartum dengan onset laktasi cepat sebanyak $22(55 \%)$ ibu postpartum dan yang mengalami onset laktasi lambat sebanyak 18 (45\%). Pada penelitian ini mayoritas ibu postpartum dengan IMT normal yaitu $25(62,5 \%)$ ibu postpartum, yang obesitas sebanyak 11 $(27,5 \%)$, bahkan yang underweight hanya sebanyak 4 (10\%). Berdasarkan data paritas menunjukkan sebanyak 26 (35\%) ibu adalah multipara, 14 (35\%) primipara. Ibu yang dilakukan IMD saat persalinan lebih banyak yaitu $22(55 \%)$ ibu, daripada ibu yang tidak dilakukan IMD 18 (45\%).

Tabel 2. Analisis Bivariabel Faktor yang Mempengaruhi Onset Laktasi di Wilayah Kota Palangka Raya $(n=40)$

\begin{tabular}{|c|c|c|c|c|c|c|}
\hline \multirow[b]{3}{*}{ Variabel } & \multicolumn{5}{|c|}{ Onset Laktasi } & \multirow{3}{*}{$\mathrm{p}$} \\
\hline & \multicolumn{2}{|c|}{ Lambat } & & \multicolumn{2}{|c|}{ Cepat (Reff) } & \\
\hline & $\mathrm{n}$ & $\%$ & $\begin{array}{c}\text { OR } \\
(95 \% \mathrm{CI})\end{array}$ & $\mathrm{n}$ & $\%$ & \\
\hline \multicolumn{7}{|l|}{ Jenis Pijat } \\
\hline Oksitosin & 13 & $65 \%$ & 5.57 & 7 & $35 \%$ & $0.026^{*}$ \\
\hline Laktasi & 5 & $25 \%$ & Reff & 15 & $75 \%$ & \\
\hline \multicolumn{7}{|c|}{ Indeks Massa Tubuh } \\
\hline Obesitas & 9 & $81.8 \%$ & 9.56 & 2 & 18.2 & \\
\hline Underweight & 1 & $25 \%$ & 0.708 & 3 & 75 & 0.079 \\
\hline Normal & 8 & $32 \%$ & Reff & 17 & 68 & \\
\hline \multicolumn{7}{|l|}{ Paritas } \\
\hline Multipara & 14 & $53.8 \%$ & 2.9 & 12 & $46.2 \%$ & \\
\hline Primipara & 4 & $28.6 \%$ & Reff & 10 & $71.4 \%$ & 0.23 \\
\hline \multicolumn{7}{|c|}{ Inisiasi Menyusui Dini } \\
\hline Tidak & 11 & $61.1 \%$ & 3.36 & 7 & $38.9 \%$ & 0.12 \\
\hline $\mathrm{Ya}$ & 7 & $31.8 \%$ & Reff & 15 & $68.2 \%$ & \\
\hline
\end{tabular}


Hubungan antara jenis pijat dengan onset laktasi terlihat bahwa ibu yang mendapatkan pijat laktasi semakin besar kemungkinan onset laktasinya cepat. Dari 15 ibu yang mendapatkan pijat laktasi, 75\% mengalami onset laktasi yang cepat. Dari 7 ibu yang mendapatkan pijat oksitosin, hanya $35 \%$ dengan onset laktasi cepat.

Dari nilai OR dapat disimpulkan bahwa ibu yang mendapatkan pijat laktasi mempunyai kecenderungan dengan onset laktasi cepat 5.57 kali lebih besar dibandingkan ibu yang mendapatkan pijat oksitosin $(p$-value $=0.026)$. Faktor risiko lainnya seperti indeks massa tubuh, paritas dan inisiasi menyusu dini secara statistik tidak mempunyai hubungan yang bermakna dengan onset laktasi pada ibu postpartum.

Tabel 3. Analisis Hubungan Onset Laktasi dengan Faktor Risiko pada Ibu Postpartum di Wilayah Kota Palangka Raya $(n=40)$

\begin{tabular}{|c|c|c|c|c|}
\hline \multirow[b]{2}{*}{ Variabel } & \multicolumn{4}{|c|}{ Onset Laktasi } \\
\hline & $\begin{array}{c}\text { Model } 1 \\
\text { OR }\end{array}$ & $\begin{array}{c}\text { Model } 2 \\
\text { OR }\end{array}$ & $\begin{array}{c}\text { Model } 3 \\
\text { OR }\end{array}$ & $\begin{array}{c}\text { Model } 4 \\
\text { OR }\end{array}$ \\
\hline \multicolumn{5}{|l|}{ Pijat } \\
\hline Laktasi & $5.571^{*}$ & $5,72 *$ & $4.79 *$ & $25.01 *$ \\
\hline Oksitosin & 1 & 1 & 1 & 1 \\
\hline \multicolumn{5}{|c|}{ Inisiasi Menyusui Dini } \\
\hline Tidak & & 3.49 & 3.54 & 4.08 \\
\hline $\mathrm{Ya}$ & & 1 & 1 & 1 \\
\hline \multicolumn{5}{|l|}{ Paritas } \\
\hline Multipara & & & 1.95 & 0.83 \\
\hline Primipara & & & 1 & 1 \\
\hline \multicolumn{5}{|l|}{ Indeks Masa Tubuh } \\
\hline Obesitas & & & & 48.29 \\
\hline Underwight & & & & 2.07 \\
\hline Normal & & & & 1 \\
\hline $\mathrm{R}^{2}(\%)$ & $15.3 \%$ & $21.6 \%$ & $23 \%$ & $49.2 \%$ \\
\hline $\mathrm{N}$ & 40 & 40 & 40 & 40 \\
\hline
\end{tabular}

Pada data jenis pijat, didapatkan hasil bahwa model 3 adalah model yang tepat dengan nilai $\mathrm{R}^{2} 23 \%$ menunjukkan bahwa variabilitas variabel independen mampu menjelaskan variabilitas variabel dependen sebesar 23\%, selebihnya dipengaruhi oleh faktor lain. Responden dengan pijat oksitosin berisiko atau berpeluang 4,79 kali untuk mengalami onset laktasi lambat dibandingkan pijat laktasi setelah mengontrol variabel inisiasi menyusu dini, paritas dan indeks masa tubuh.

\section{PEMBAHASAN}

Oksitosin adalah hormon yang dapat membuat rileks, menurunkan tekanan darah dan kadar kortisol (hormon yang berpengaruh terhadap stres). Oksitosin dapat meningkatkan ambang rasa nyeri, memiliki efek menurunkan kecemasan, serta dapat merangsang berbagai interaksi sosial yang 
positif. Oksitosin dilepaskan oleh berbagai jenis stimulasi sensorik seperti sentuhan dan kehangatan serta mekanisme psikologi. Ini berarti bahwa dengan interaksi sosial yang positif seperti melibatkan sentuhan dan dukungan psikologi dapat membantu sekresi hormon oksitosin. Menurut teori mengatakan bahwa, oksitosin juga berperan penting dalam memfasilitasi berbagai fungsi fisiologis seperti menginduksi rasa nyeri persalinan dan laktasi.

Dalam proses laktasi, sekresi hormon oksitosin dapat dirangsang dengan melibatkan sentuhan seperti pemijatan. Pijat yang dapat diupayakan untuk meningkatkan proses laktasi yaitu pijat laktasi dan pijat oksitosin. Pijat laktasi adalah gerakan pemijatan pada bagian-bagian tubuh tertentu seperti kepala, leher, bahu, punggung, dan payudara untuk memperlancar proses menyusui. Pada keadaan-keadaan tertentu pijat laktasi dapat dilakukan untuk menstimulasi produksi ASI, misalnya membantu proses induksi menyusui (untuk ibu adopsi/ibu angkat/belum pernah menyusui).

Pijat oksitosin adalah pemijatan tulang belakang pada daerah punggung mulai dari costae (tulang rusuk) ke 5-6 memanjang kedua sisi tulang belakang sampai ke scapula (tulang belikat) yang akan mempercepat kerja saraf parasimpatis, saraf yang berpangkal pada medula oblongata dan pada daerah sacrum dari medula spinalis, merangsang hipofise posterior untuk mengeluarkan oksitosin, oksitosin menstimulasi kontraksi sel-sel otot polos yang melingkari duktus laktiferus kelenjar mamae menyebabkan kontraktilitas myoepitel payudara sehingga dapat meningkatkan pemancaran ASI dari kelenjar mammae. (16)

Subjek penelitian ini adalah ibu postpartum dengan persalinan normal sebanyak 40 responden yang bersedia dilakukan pemijatan dan diobservasi sampai terjadinya onset laktasi. Terdapat hubungan onset laktasi yang bermakna dalam hal ini dapat disebabkan karena pada pijat laktasi dilakukan pemijatan pada lebih banyak titik pada bagian tubuh seperti di kepala, leher, bahu, punggung, dan payudara, serta durasi pemijatan yang lebih lama yaitu \pm 30 menit. Sedangkan pijat oksitosin dilakukan pemijatan hanya pada daerah punggung dengan durasi pemijatan selama \pm 15 menit. Kemudian dengan adanya pemijatan pada daerah payudara juga dapat lebih meningkatkan produksi dan pengeluaran ASI, karena jaringan payudara banyak berisi pembuluh getah bening dan pembuluh darah, pembuluh yang terhambat menjadi penyebab kurang lancarnya produksi dan aliran.

Penelitian ini sejalan dengan hasil penelitian sebelumnyha yang menunjukan rata-rata skor kelancaran produksi ASI sebelum diberi perlakuan pijat laktasi didapatkan skor rata-rata 1,30 sedangkan setelah diberikan perlakuan pijat laktasi didapatkan skor rata-rata 6,26 yang disimpulkan bahwa pijat laktasi memiliki pengaruh terhadap produksi ASI pada ibu postpartum primigravida dengan $p$-value 0,000. (17) Faktor risiko lain seperti inisiasi menyusu dini, paritas dan status gizi dalam penelitian ini tidak berpengaruh secara statistik terhadap onset laktasi. 


\section{KESIMPULAN}

Onset laktasi pada ibu postpartum yang mendapatkan pijat laktasi lebih cepat daripada ibu postpartum yang mendapatkan pijat oksitosin. Inisiasi menyusu dini, paritas, dan indeks masa tubuh terbukti tidak mempengaruhi onset laktasi pada ibu postpartum.

\section{SARAN}

Perlu dioptimalkan pemberian pendidikan dan pelayanan kesehatan oleh tenaga kesehatan khususnya bidan bagi ibu sejak awal kehamilan sampai dengan awal persalinan berhubungan dengan keberhasilan pemberian ASI eksklusif, pijat pada ibu postpartum khususnya pijat laktasi dapat menjadi pelayanan tambahan di Praktik Mandiri Bidan maupun di pelayanan kesehatan lainnya.

\section{DAFTAR PUSTAKA}

1. Kementerian Kesehatan RI. Data dan Informasi Profil Kesehatan Indonesia 2016. 2017.

2. Dinas Kesehatan Kalimantan Tengah. Profil Dinas Kesehatan Kalimantan Tengah [Internet]. Dinas Kesehatan Provinsi Kalimantan Tengah. 2017. Available from: http://www.depkes.go.id/resources/download/profil/PROFIL_KES_PROVINSI_2016/21_ Kalteng_2016.pdf

3. Institute of Medicine. Nutrition during lactation. Washington DC: National Academic Press; 1991.

4. Saarinen UM, Kajosari M. Breastfeeding as prophylaxis against atopic disease; prospective follow-up study until 17 years old. Lancet. 1995;346:1065-9.

5. Roesli Utami. Makalah disampaikan pada Seminar Telaah Mutakhir tentang ASI. Jakarta: FAOPS-Perinasia; 2001.

6. Anderson JW, Johnstone B, Remley D. Breastfeeding and cognitive development: a metaanalysis. Am J Clin Nutr. 1999;70:525-35.

7. Uauy R, Andraca de I. Human milk and breastfeeding for optimal mental development. J Nutr. 1995; 125:2278S-80S.

8. Besar DS. Metode Amenorea Laktasi. Makalah yang disampaikan pada Seminar Telaah Mutakhir tentang ASI. Jakarta: FAOPS-Perinasia; 2001.

9. Davies-Adetugbo A OE. Maternal education, breastfeeding behaviours and lactational amenorrhea: studies among two ethnic communities in Ile Ife, Nigeria. Nutr Health. 1996;11:115-26.

10. Simandjuntak D. Faktor-faktor yang berhubungan dengan pemberian makanan pendamping ASI dini pada bayi di Kecamatan Pasar Rebo, Kotamadya Jakarta Timur tahun 2001 [Internet]. Universitas Indonesia; 2002. Available from: http://lib.ui.ac.id/ bo/uibo/detail.jsp?id=72569\&lokasi=lokal

11. Utomo B. The Slowing Progress of Breastfeeding Promotion Program in Indonesia: Causes and Recommendation, Kumpulan Makalah Diskusi Pakar bidang Gizi tentang ASI-MP ASI,Antropometri, BBLR, Kerjasama antara Persatuan Ahli Gizi Indonesia, LIPI, UNICEF. 2000.

12. Daniel J. Hruschka, Daniel W. Sellen, Aryeh D. Stein, Reynaldo Martorel. Delayed Onset Laktasion And Of Ending Full Breastfeeding Early In Rutal Guatemala. J Nutr [Internet]. 
2003;133(8):2592-2599. Available from: https://academic.oup.com/ jn/ article/ 133/ 8 / $2592 / 4688023$

13. Rivers, L.A.N, Chantry, C.J., Peerson, J.M., Cohen, R.J., Dewey, K.G. Delayed Onset Of Lactogenesis Among Firsttime Mothers Is Related To Maternal Obesity And Factors Associated With Ineffective Breastfeeding. Am J Clin Nutr [Internet]. 2010;92(3):574-84. Available from: https://academic.oup.com/ajcn/article/92/3/574/4597439

14. Sari LP, Salimo H, Budihastuti UR. Optimizing the Combination of Oxytocin Massage and Hypnobreastfeeding for Breast Milk Production among Post-Partum Mothers. J Matern Child Heal [Internet]. 2017;1(1):20-9. Available from: oxytocin massage, hypnobreastfeeding, breast milk production, post-partum

15. Hapitria P. Pijat Laktasi. Poltekkes Kemenkes Palangka Raya; 2017.

16. Hajerah, Mawarti R. Hubungan Status Gizi dengan Onset Laktasi pada Ibu Postpartum di RS PKU Muhammadiyah Yogyakarta [Internet]. SEKOLAH TINGGI ILMU KESEHATAN 'AISYIYAH YOGYAKARTA; 2015. Available from: http://digilib.unisayogya.ac.id/511/

17. Lestari RDA. Pengaruh Pijat Laktasi Terhadap Produksi Asi Pada Ibu Primigravida (Studi Pada Ibu Postpartum di Desa Rejoyoso, Kec. Bantur, Kab. Malang). Universitas Muhammadiyah Malang; 2016. 